\title{
TEMPORALITAS PADA VERBA DALAM BAHASA DANI BARAT
}

\author{
Supardi \\ FKIP Universitas Cenderawasih \\ email: supardi_uncen@yahoo.co.id
}

\begin{abstract}
Abstrak
Penelitian ini bertujuan mendeskripsikan aspek temporalitas pada verba dalam bahasa Dani Barat (BDB) di Papua. Data diambil dari laporan penelitian Purba dkk. (1994) berjudul Morfologi Bahasa Dani Barat. Pembuktian temporalitas dilakukan dengan metode distribusional dilengkapi teknik permutasi dan lesap. Hasil penelitian menunjukkan bahwa BDB memiliki sembilan bentuk verba: 1) berpelaku tunggal kala kini, 2) berpelaku tunggal kala lampau dekat, 3) berpelaku tunggal kala lampau jauh, 4) berpelaku tunggal kala mendatang, 5) berpelaku jamak kala kini, 6) berpelaku jamak kala lampau dekat, 7) berpelaku jamak kala lampau jauh, 8) berpelaku jamak kala mendatang, dan 9) kala kebiasaan. Bentuk verba temporalitas diklasifikasikan dalam dua kelompok: delapan verba sesuai waktu berlangsungnya peristiwa dan satu verba bentuk kebiasaan. Kesembilan verba yang menunjukkan waktu dibedakan atas subjek tunggal dan jamak.
\end{abstract}

Kata kunci: verba, aspektualitas, temporalitas, bahasa Dani Barat

\section{TEMPORALITY OF VERBS IN THE WESTERN DANI LANGUAGE}

\begin{abstract}
This study aims to describe the temporality aspect of verbs in the Western Dani Language (WDL) in Papua. The data were from Morfologi Bahasa Dani Barat, a research report by Purba, et al. (1994). The temporality was proved by the distributional method supplemented by permutation and deletion techniques. The findings show that WDL has nine verb forms. Those are ones with: 1 ) a singular subject for the present tense, 2) a singular subject for the recent past tense, 3) a singular subject for the remote past tense, 4) a singular subject for the future tense, 5) a plural subject for the present tense, 6) a plural subject for the recent past tense, 7) a plural subject for the remote past tense, 8) a plural subject for the future tense, and 9) the habitual present tense. Temporality verb forms are classified into two groups: eight verbs based on the time an event occurs and one verb of a habitual event. The nine verbs showing time are distinguished on the basis of singular and plural subjects.
\end{abstract}

Keywords: verbs, aspectuality, temporality, Western Dani Language

\section{PENDAHULUAN}

Verba dalam Bahasa Dani Barat (BDB) terletak sesudah nomina. Susunan katanya dalam kalimat secara umum adalah SOP (Purba, 1994 dan 2000). Hal ini tentu berbeda dengan BI karena dalam BI verba (predikat) terletak sesudah subjek. Hal ini dapat diperhatikan dalam contoh kalimat di bawah ini.

(01) Saya makan nasi.

(02) An kom nangge.

saya keladi makan(skg tgl)

'Saya sedang makan keladi'

(02a)*An nangge kom 
Contoh kalimat di atas secara struktur antara BI dan BDB sangat jelas perbedaannya. Pengubahan bentuk kalimat (02) menjadi seperti kalimat (02a) tidak dapat dilakukan. Pengubahan struktur kalimat (02) menjadi struktur seperti dalam BI (02a) tidak berterima. Kalimat (02) dapat diubah dalam bentuk lampau (dekat). Hasil pengubahannya seperti tampak pada (02b). Kalimat (02) dapat diganti subjeknya dengan nir 'kami'. Penggantian subjek ini akan menghasilkan verba yang berbeda secara struktur $(02 b)$, tetapi makna verba itu sama dengan kalimat (02).

(02b) Nir kom nanggarak.

kami sdh makan lp (jmk)

'Kami sudah makan keladi'

Dengan subjek yang sama, tetapi verba berbentuk nanggwarak akan menjadi kalimat seperti (02c) di bawah ini.

(02c) Nir kom nanggwarak. kami sdh makan (lp/jmk)

'Kami sudah makan keladi'

Perbedaan makna kalimat (02b) dengan (02c) adalah bahwa peristiwa makan pada (02b) berlalu belum lama, sedangkan pada (02c) peristiwa makan sudah berlalu lama. Memperhatikan contoh kalimat dalam BDB di atas cukup jelas menunjukkan bahwa verba dapat berubah strukturnya karena perbedaan subjek dan sekaligus waktu berlangsungnya kegiatan. Hal ini sangat berbeda tentunya dengan BI. Verba dalam BI tidak mengenal perbedaan karena subjek dan waktu berlangsungnya kegiatan. Djajasudarma, (1999) seperti dikutip oleh Sulistiyani (2011:3) menyatakan untuk mengungkapkan waktu berlangsungnya kegiatan dalam BI digunakan nomina temporal. Dalam bahasa-bahasa Papua non-Austronesia pada umumnya verba berubah karena pengaruh subjek sebagai prefiks seperti misalnya dalam bahasa Biak (Fautngil, 1991).

Menyimak contoh verba di atas permasalahan kala dalam BDB dapat diru- muskan sebagai berikut. Bagaimanakah bentuk verba temporalitas dalam BDB? Apa saja makna verba temporalitas yang terkandung dalam BDB?

Sehubungan dengan rumusan masalah yang diuraikan di atas, tujuan kajian ini meliputi hal sebagai berikut. Yakni mendeskripsikan bentuk verba temporalitas dalam BDB. Untuk mendeskripsikan makna yang diungkap dalam verba temporalitas dalam BDB.

Sebuah kategori dalam suatu bahasa yang dapat diberi keterangan oleh unsur lain terutama adverbia. Adverbia adalah sebuah kategori yang dapat memberi keterangan pada nomina, pronomina, verba, adjektiva, numeralia termasuk adverbia itu sendiri. Adverbia yang secara khusus memberi keterangan pada unsur verba disebut adverbia verbal (Alwi dkk, 1998) dan (Wedhawati dkk, 2001). Kata-kata ini misalnya: akan, sedang, sudah, sendirian, hampir, dll. adalah adverbia. Unsur ini (keterangan) dalam bahasa lain khususnya dalam bahasa-bahasa Eropa dan Skandinavia menyatu dalam verba yang disebut sebagai aspek. Dalam bahasa keturunan Austronesia memang tidak ditemukan seperti dalam BI. Namun, dalam bahasa-bahasa Papua pada umumnya terdapat unsur verba yang seperti ini (Purba, 1987 dan 1999), (Fautngil, 1991), lihat pula (Purba, 2000:83).

(03) Y- os i. saya pukul ia 'Saya memukul dia'

(04) S- an ui. mereka makan papeda 'Mereka makan papeda.'

Pronomina 'saya' dalam bahasa Biak adalah aya dan 'mereka' adalah si, tetapi ketika pronomina (ini) digunakan sebagai subjek tidak pernah dimunculkan, sebagai penggantinya digunakan prefiks. Prefiks $y$ - untuk 'saya' dan prefiks s-untuk 'mereka', sehingga kalimat tampak seperti kalimat nomor (03) dan (04) di atas. 
Dalam bahasa-bahasa Papua terdapat verba yang mengandung unsur subjek dan sekaligus objek. Kasus seperti ini terdapat dalam bahasa Kayu Pulau. Sebuah bahasa yang terdapat di wilayah Jayapura. Hasil penelitian menunjukkan bahwa bahasa Kayu Pulau, Tobati,dan Mairasi unsur verba mengandung subjek dan objek sekaligus (Purba, 2000). Bahasa Kayupulau dan Tobati termasuk bahasa Austronesia, tetapi telah mendapat pengaruh bahasa Papua. Contoh di bawah ini dalam bahasa Tobati dan Kayu Pulau.

(05) Ntrica nhut r-ndom-rok. mereka saya memperhatikan

'Mereka memperhatikan saya'

(06) Rie tnito r-ioro-tni.

mereka kami menikam.

'Mereka menikam kami'

Kalimat (06) adalah contoh dalam bahasa Tobati. Verba rndomrok terdiri atas prefiks $r$-sebagai penanda subjek persona ketiga jamak, kata dasar ndom 'memperhatikan' dan sufiks -rok sebagai penanda objek persona pertama tunggal.

Dalam bahasa Jawa ragam sastra, verba dapat dilekati sufiks penanda subjek. Bentuk sufiks ini adalah : $-a,-n a,-a n a$, dan -en (Sudaryanto, 1994).

(07) Ya ya Gatot pangestuku tampanana. ya, ya Gatotkaca izinku terimalah

'Ya, ya Gatotkaca terima izinku.'

Kajian aspektualitas dalam bahasa Indonesia diawali oleh Fokker pada tahun 1950. Fokker menyebut aspektualitas dengan istilah aspek. Perbedaan bentuk pengungkapan antara bahasa asing ( $\mathrm{Ru}-$ sia) dengan bahasa-bahasa di Indonesia diungkapkan oleh Fokker (1983: 160) sebagai berikut.

Dalam bahasa Rusia bermacammacam aspek diungkapkan dengan sistem terurai yang amat halus dari bentuk-bentuk tata bahasa. Di sana aspek menjadi suatu kategori tata bahasa. Artinya di sana suatu pengungkapan suatu kejadian selamanya terikat pada cara penggambaran tertentu dalam pikiran. Dalam bahasabahasa Eropa aspek itu rapat terjalin dalam perbedaan waktu. Di situ waktu dan aspek menjadi suatu keseluruhan yang tidak dapat dipisah-pisahkan, bertentangan dengan bahasa-bahasa (di) Indonesia, yakni perbedaan waktu yang formal tidak ada sama sekali.

Pernyataan Fokker di atas sejalan dengan pernyataan Dahl (1981), Djajasudarma (1990), Britton (1990), dan Tajuddin (1992) yang menyatakan bahwa dalam rangka pengungkapan aspektualitas terdapat dua perbedaan konsep antara pandangan barat dan timur. Pandangan timur tradisi Slavia diwakili bahasa Rusia dan pandangan barat Aristotle diwakili oleh bahasa Inggris.

Kajian aspektualitas di Indonesia kemudian dilanjutkan oleh Tajuddin 1992 dan disusul oleh Sumarlam (1994). Tajuddin mengkaji dalam BI sedangkan Sumarlam mengkaji dalam bahasa Jawa. Simpulan yang disampaikan oleh mereka adalah bahwa aspektualitas dan temporalitas BI dan bahasa Jawa diungkapkan dalam bentuk leksikal (ayo, coba, mari, silakan). Lihat pula Riyono (2009) yang mengutip pendapat Tajuddin. Pada awalnya baik Tajuddin maupun Sumarlam menggunakan istilah keaspekan, tetapi atas dasar pendapat berbagai pakar yang dibaca kemudian digunakanlah istilah yang sejalan dengan kedua istilah lainnya (modalitas dan aksionalitas).

Tiga subkategori semantik verba dalam linguistik umum adalah aspektualitas, temporalitas, dan modalitas. Aspektualitas dan temporalitas mempelajari sifat-sifat keberlangsungan situasi dilihat dari segi waktu yang menyertai keberlangsungan situasi tersebut. Adapun modalitas mempelajari situasi dari sudut pandang bermacam-macam sikap pembicara terhadap situasi yang berlangsung. Ketiga subkategori ini dalam bahasabahasa tertentu termasuk kategori gramatikal. Bagaimana aspektualitas digam- 
barkan dalam Bahasa Dani Papua Barat. Uraian ini akan menjawab pertanyaan dimaksud.

Aspektualitas berasal dari kata aspect 'aspek'. Kata ini merupakan terjemahan dari istilah Rusia vid. Aspektualitas diilhami oleh gejala aspektualitas vid 'aspek' dalam bahasa Rusia. Atas dasar itu para linguis menggunakan istilah aspek juga untuk gejala aspektualitas yang bukan aspek melainkan aksionalitas dalam bahasa-bahasa lain (non-Slavia). Tajuddin (2006: 9) mendefinisikan aspektualitas berdasarkan sepuluh definisi yang telah diberikan oleh pakar terdahulu. Definisi beliau adalah subkategori semantik fungsional yang mempelajari bermacam-macam sifat unsur waktu internal situasi (peristiwa, proses, atau keadaan), yang secara lingual terkandung di dalam semantik verba. Dijelaskan lebih lanjut bahwa definisi di atas berlaku bagi gejala aspektualitas pada umumnya, tidak terbatas pada aspek dan aksionalitas saja. Unsur waktu aspektualitas bersifat internal, juga berurusan dengan temporalitas yang unsur waktunya bersifat eksternal.

Perbedaan aspektualitas dan temporalitas dapat dijelaskan sebagai berikut. Pada temporalitas unsur waktu bersifat lokatif mengacu pada waktu absolud pada umumnya. Dengan demikian, situasi dapat berlangsung sebelum waktu ujaran, bersamaan dengan waktu ujaran, atau sesudah waktu ujaran. Pada aspektualitas waktu bukan merupakan lokasi tempat berlangsungnya situasi, melainkan situasi itu sendiri yang menjadi lokasi tempat hadirnya waktu. Jadi, waktu berada di dalam situasi, bukan di luar situasi. Singkatnya bahwa temporalitas waktu beranalogi dengan sebutan dulu, sekarang, nanti, pada aspektualitas waktu mengacu pada ukuran panjang/lama tak terbatas, panjang/lama terbatas, pendek/sebentar sampai sekejab, atau terputus-putus (Tajuddin, 2006:10). Dilanjutkan oleh beliau temporalitas tergolong kategori diektik, unsur waktu bersifat eksternal, sedangkan aspektualitas tergolong nondiektik waktu bersifat internal. Sifat unsur waktu dalam aspektualitas dan temporalitas digambarkan dalam kalimat bahasa Inggris sebagai berikut. Temporalitas dan aspektualitas dapat dibedakan atas pertanyaan kapan dan berapa lamal kali. Kapan (kemarin, sedang, akan) untuk mengecek temporalitas sedangkan berapa lama/kali (lama, sebentar, baru saja) untuk mengecek aspektualitas.

(8) a. John is eating soup.

'John sedang makan sup'.

b. John was eating soup.

'(Waktu itu) John sedang makan sup'.

c. John will be eating soup.

'John akan (sedang) makan sup'.

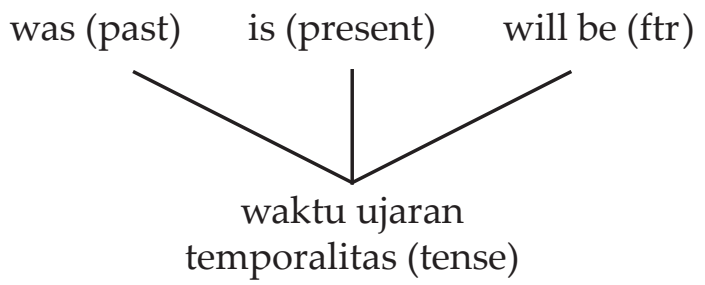

Dilihat dari segi waktu tense, kalimat (8a) menggambarkan waktu kini (is), kalimat (8b) menggambarkan waktu lampau (was), dan kalimat (8c) menggambarkan kala mendatang (future, will be).

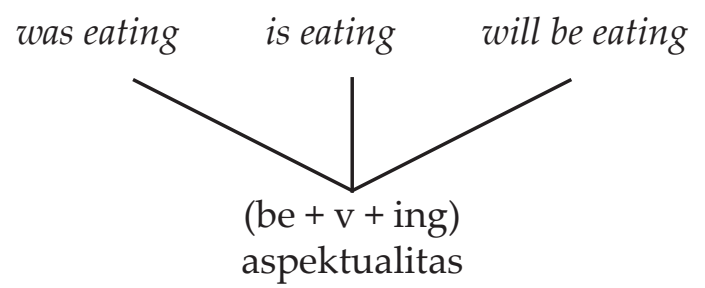

Adapun dilihat dari sudut pandang kategori aspektualitas, ketiga kalimat tersebut menggambarkan aspektualitas progresif karena ketiganya berbentuk $b e+v+i n g$. Contoh berikut Tajuddin menyertakan dalam bahasa Rusia. 
(09) On cital knigu, kogda japrisel. dia baca-if/lp buku ketika saya datang-pf/lp. 'Ia sedang membaca sebuah buku ketika saya datang'

Sufiks - $l$ pada kalimat di atas menggambarkan temporalitas, dalam hal ini kala lampau. Dalam Bahasa Inggris temporalitas diungkapkan dalam kategori kala. Bentuk kala diungkapkan melalui proses morfologi infleksional dengan sufiks - ed atau modifikasi internal seperti dalam kata sang, sing, sung ataupun dalam bentuk suplisi: is, are, was, dsb. Dalam bahasa Jepang aspektualitas dan temporalitas di diungkap melalui empat bentuk akar verba berikut: $v$-ru,v-ta, v-te iru, dan $v$-te ita (Rostini, 2011: 204).

Temporalitas juga terdapat dalam BDB. Sebuah bahasa yang terdapat di pedalaman Papau. Masyarakat penutur bahasa ini dikenal dengan nama suku Dani. Kategori temporalitas dalam BDB terjadi dalam proses infleksional seperti pada contoh di bawah ini.

(10) An kom nanggerak.

saya keladi sudah makan

'Saya sudah makan keladi'

(11) An kom nangge.

saya keladi makan

'Saya makan keladi'

Sufiks -gerak pada kalimat di atas menggambarkan temporalitas, dalam hal ini kala lampau dengan subjek orang pertama tunggal. Kalimat (10) dengan melesapkan unsur sufiks -gerak kalimat berubah makna dari kala lampau ke kala kini.

BDB merupakan salah satu kelompok bahasa asli Papua yang masuk dalam Filum Trans New Guinea (Non-Austronesia). Salah satu dari filum ini adalah Stok DaniKwerba. Stok ini terdiri atas dua famili yakni Great Dani dan Kwerba. Sub-Famili Great Dani memiliki 3 subfamili, salah satunya adalah bahasa Dani. Bahasa Dani memiliki 2 subfamili yakni Grand Dani Valley, masyarakat umum menyebutnya Bahasa Dani Lembah dan Wester Dani atau Bahasa Dani Barat (Wurm, 1982: 1951).

Informasi kebahasaan bahasa ini diperoleh dari Purba dkk. Purba dkk pada tahun 1993 meneliti Fonologi. Pada tahun 1994 oleh Purba dkk. dilanjutkan meneliti Morfologi. Purba (1994: 108) dkk. memberikan simpulan bahwa BDB memiliki tenses 'kala'. Penelitian yang dilakukan oleh Purba dkk. ini bersifat normatif. Sifat penelitian hanya menunjukkan bahwa BDB memiliki kala. Unsur kala yang ada tidak dibuktikan. Hal ini disebabkan metode kajian yang digunakan adalah metode analisis gramatikal. Metode ini bersifat menunjukkan bukan membuktikan. Lebih lanjut dituliskan bahwa ada sembilan bentuk verba lengkap dengan perubahan bentuk verbanya. Kemudian, diberi contoh perubahan bentuk verba dari bentuk pertama sampai ke-9 seperti berikut ini. Verba pelaku tunggal 'saya' kala 1) sekarang nangge 'pergi, tunggal 'kamu', kala 2) lampau dekat nanggerak, pelaku tunggal 'dia', kala 3) lampau jauh nangnegerak, pelaku tunggal 'saya', kala 4) mendatang nagin, pelaku jamak 'mereka', kala 5) sekarang nanggwi, pelaku jamak 'mereka', kala 6) lampau dekat nanggarak, pelaku jamak 'mereka', kala 7) lampau jauh nangnegwarak, pelaku jamak, kala 8) mendatang narugun, kala 9) kebiasaan pelaku tunggal nangge, pelaku jamak nanggo.

\section{METODE}

Penelitian atau kajian ini menggunakan metode deskripsi. Untuk dapat menggambarkan kala dalam BDB digunakan kajian struktural distribusional. Data penelitian ini diambil dari laporan hasil penelitian yang dilakukan oleh Purba dkk. (1994). Data berupa kalimat yang terdapat unsur kala kemudian dicatat dalam kelompok data yang berbeda-beda ber- 
dasarkan bentuk morfologinya. Data ini kemudian dianalisis berdasarkan penggunaan BDB sehari-hari yang disebut metode agih (Djajasudarma, 1995 dan Mahsun, 2012). Selanjutnya digunakan teknik dasar bagi unsur langsung. yaitu membagi, memilah-milah data berdasarkan bentuk morfologinya. Teknik dasar dilengkapi dengan teknik sulih, lesap, parafrasa, dan permutasi (Dajasudarma, 1995 dan Mahsun, 2012).

\section{HASIL DAN PEMBAHASAN}

Unsur bahasa sebagai penanda waktu berlangsungnya suatu kegiatan dalam BDB berbentuk sufiks. Sufiks ini secara struktural melekat dalam sebuah verba membentuk unsur bahasa yang disebut temporalitas. Hasil kajian Purba dkk (1994) menunjukkan bahwa terdapat sembilan bentuk verba sesuai dengan perubahan waktu. Kesembilan bentuk verba dengan perubahan waktu ini tersusun sangat teratur. Apakah kegiatan itu sudah (past) berlangsung untuk pelaku tunggal dan jamak, sedang berlangsung untuk pelaku tunggal dan jamak (present), akan berlangsung untuk pelaku tunggal dan jamak (future), atau merupakan kebiasaan juga untuk pelaku tunggal dan jamak. Secara lengkap temporalitas pada verba dalam $B D B$ dapat diuraikan sebagai berikut.

\section{Verba Berpelaku Tunggal Kala Kini}

Verba kala kini atau kata kerja yang menunjukkan waktu sekarang dalam BDB ialah semua verba bentuk pertama pelaku tunggal yang berakhir dengan bunyi -ngge, -ge, dan atau -ke. Kata ini merupakan verba dasar.Dengan demikian, verba dasar dalam BDB selalu berakhir dengan bunyi -ke, -ge atau -ngge (Purba, 1994: 57).

(12) An mbi nangge.

saya ubi makan

'Saya makan ubi'.
(13) Kar mbi lake.

kamu ubi masak

'Kamu memasak ubi.'

(14) Markus nage.

Markus pergi

'Markus pergi'.

(15) Ar mbi nangge.

dia biasa ubi makan

'Dia makan ubi'.

\section{Verba Berpelaku Tunggal Kala Lampau Dekat}

Verba kala lampau dekat ialah kata kerja penuh yang berakhir dengan sufiks -rak. Bentuk kata kerja kedua pelaku tunggal.

(16) An mbi nanggerak. saya ubi makan sudah

'Saya sudah makan ubi'.

(17) Kar mbi nanggerak. engkau ubi makan.

'Engkau sudah makan ubi'.

(18) Ar mbi nanggerak.

dia ubi makan

'Dia makan ubi'.

Pelesapan sufiks - rak pada kalimat di atas akan menyebabkan kalimat berubah makna. Verba akan kembali ke bentuk pertama pelaku tunggal kala kini. Dengan demikian tetap berterima, tetapi maknanya berubah.

(12a) An mbi nangge.

saya ubi makan

'Saya makan ubi'.

\section{Verba Berpelaku Tunggal Kala Lampau} Jauh

Bentuk verba kala lampau jauh pelaku tunggal ialah semua kata dengan sufiks -gerak. Verba dasar yang berakhir dengan -ngge akan berubah menjadi -ne, sedangkan verba dasar yang berakhir dengan -ke dan -ge menjadi re.

(19) An mbi nangnegerak. saya ubi makan sudah 'Saya sudah (lama) makan ubi'. 
(20) Kar mbi laregerak. kamu ubi masak

'Kamu sudah (lama) memasak ubi'.

(21) Ar mbi wonok naregerak.

dia ubi membawa

'Dia sudah (lama) membawa ubi'.

Pelesapan sufiks -gerak pada kalimat di atas akan menyebabkan kalimat berubah makna. Verba akan kembali ke bentuk pertama pelaku tunggal kala kini. Dengan demikian tetap berterima, tetapi maknanya berubah.

(20a) Nir mbi lake. kami ubi masak

'Kami sudah (lama) memasak ubi'.

(21a) Ar mbi wonok nage.

dia ubi membawa

'Dia membawa ubi'.

\section{Verba Berpelaku Tunggal Kala Menda- tang}

Bentuk verba kala mendatang pelaku tunggal ialah semua kata dengan sufiks -igin. Verba dasar yang berakhir dengan -ngge akan berubah menjadi -ne, sehingga menjadi nigin. Adapun verba dasar yang berakhir dengan -ke dan -ge menjadi $r$, sehingga menjadi rigin.

(22) An mbi nangrigin.

saya ubi makan

'Saya akan makan ubi'.

(23) Kar mbi wagarigin.

Engkau ubi memberi

'Engkau akan memberi ubi'.

(24) Ar mbi kumarigin.

dia biasa ubi mencuri

'Dia akan mencuri ubi'.

Pelesapan sufiks -igin pada kalimat di atas akan menyebabkan kalimat berubah makna. Verba akan kembali ke bentuk pertama pelaku tunggal kala kini. Dengan demikian tetap berterima, tetapi maknanya berubah.

(23a) Kar mbi wagage.

Engkau ubi memberi

'Engkau memberi ubi'. (24a) Ar mbi kumake.

dia biasa ubi mencuri

'Dia mencuri ubi'.

\section{Verba Berpelaku Jamak Kala kini}

Bentuk verba kala kini pelaku jamak ialah semua kata yang bersufiks - gwi atau -kwi. Verba dasar yang berakhir dengan -ngge dan -ge akan berubah menjadi -gwi. Adapun verba dasar yang berakhir dengan -ke akan menjadi -kwi.

(25) Nir mbi nanggwi.

kami ubi makan

'Kami makan ubi'.

(26) Ir mbi pegwi.

mereka ubi meletakkan

'Mereka meletakkan ubi'.

(27) Kir mbi kumakwi.

kalian ubi mencuri

'Kalian mencuri ubi'.

Pelesapan sufiks - gwi atau -kwi pada kalimat di atas akan menyebabkan kalimat tidak berterima. Verba akan kembali ke bentuk pertama pelaku tunggal kala kini. Dengan demikian, pengubahan bentuk verba karena pelesapan unsur - gwi atau kwi tidak berterima. Agar berterima, subjek harus diganti dengan pelaku tunggal, seperti (25b), (26b), dan (27b).

(25a) *Nir mbi nangge.

kami ubi makan

'Kami makan ubi.'

(26a) *Ir mbi pege.

mereka ubi meletakkan

'Mereka meletakkan ubi' .

(27a) *Kir mbi kumake.

kalian ubi mencuri

'Kalian mencuri ubi' .

(25b) An mbi nangge.

saya ubi makan

'Saya makan ubi'.

(26b) Kar mbi pege.

engkau ubi meletakkan

'Engkau meletakkan ubi'.

(27b) Ar mbi kumake.

dia ubi mencuri

'Kalian mencuri ubi'. 


\section{Verba Berpelaku Jamak Kala Lampau Dekat}

Bentuk verba kala lampau dekat ialah semua kata bersufiks -garak atau -karak. Verba dasar yang berakhir dengan -ngge dan -ge akan berubah menjadi -garak. Adapun verba dasar yang berakhir dengan -ke akan menjadi -karak.

(28) Nir mbi nanggarak.

kami ubi makan

'Kami sudah makan ubi'.

(29) Ir mbi pegarak.

Mereka ubi meletakkan

'Mereka sudah meletakkan ubi'.

(30) Kir mbi kumakarak.

kalian ubi mencuri

'Kalian sudah mencuri ubi'.

Pelesapan sufiks -garak atau -karak ada kalimat di atas akan menyebabkan kalimat tidak berterima (28a), (29a), dan (30a) agar berterima subjek harus diganti dengan pelaku tunggal, seperti (25b), (26b), dan (27b). Pelesapan akan menye-babkan verba kembali ke bentuk pertama pelaku tunggal kala kini. Dengan demikian, perubahan bentuk verba karena pelesapan unsur-garak atau -karak tidak berterima.

(28a) *Nir mbi nangge.

kami ubi makan

'Kami sudah makan ubi'.

(29a) * Ir mbi pege.

Mereka ubi meletakkan

'Mereka sudah meletakkan ubi'.

(30a) *Kir mbi kumake.

kalian ubi mencuri.

'Kalian sudah mencuri ubi'.

\section{Verba Berpelaku Jamak Kala Lampau} Jauh

Bentuk verba kala lampau jauh ialah semua kata bersufiks -gwarak atau-kwarak. Verba dasar yang berakhir dengan -ngge dan -ge akan berubah menjadi ne. Adapun verba dasar yang berakhir dengan -ke akan menjadi re-. Dengan demikian bentuknya akan menjadi negwarak dan regwarak.
(31) Nir mbi nangnegwarak.

kami ubi makan sudah

'Kami sudah lama makan ubi'.

(32) Ir mbi penegwarak.

mereka ubi meletakkan

'Mereka sudah lama meletakkan ubi'.

(33) Kir mbi kumaregwarak.

kalian ubi mencuri

'Kalian sudah lama mencuri ubi'.

Pelesapan sufiks -grwarak pada kalimat di atas akan menyebabkan kalimat tidak berterima (31a), (32a), dan (33a) agar berterima subjek harus diganti dengan pelaku tunggal, seperti (25b), (26b), dan (27b). Pelesapan akan menyebabkan verba kembali ke bentuk pertama pelaku tunggal kala kini. Dengan demikian pengubahan bentuk verba karena pelesapan unsur -gwarak tidak berterima.

(31a) *Nir mbi nangge. kami ubi makan sudah 'Kami sudah lama makan ubi'.

(32a) *Ir mbi pege. mereka ubi meletakkan 'Mereka sudah lama meletakkan ubi'

(33a) *Kir mbi kumake. kalian ubi mencuri

'Kalian sudah lama mencuri ubi'.

Verba Berpelaku Jamak Kala Mendatang

Bentuk verba kala lampau jauh ialah semua kata bersufiks -gun. Verba dasar yang berakhir dengan -ngge akan berubah menjadi $n$. Adapun verba dasar yang berakhir dengan -ke akan menjadi $r$-. Dengan demikian bentuknya akan menjadi -nugundan -rugun.

(33) Nir mbi nangnugun. kami ubi makan akan 'Kami akan makan ubi'.

(34) Ir mbi perugun. mereka ubi meletakkan akan 'Mereka akan meletakkan ubi'.

(35) Kir mbi kumarugun. kalian ubi mencuri akan 'Kalian akan mencuri ubi'. 
Pelesapan sufiks -gun pada kalimat di atas akan menyebabkan kalimat tidak berterima. Agar berterima subjek harus diganti dengan pelaku tunggal, seperti (25b), (26b), dan (27b). Pelesapan akan menyebabkan verba kembali ke bentuk pertama pelaku tunggal kala kini. Dengan demikian pengubahan bentuk verba karena pelesapan unsur -gun tidak berterima.

\section{Verba Kala Kebiasaan}

Bentuk verba kala kebiasaan perlu adanya kata bantu yang diletakkan sesudah subjek dan sebelum nominanya. Bentuk verba dipengaruhi oleh pelaku baik tunggal maupun jamak. Bentuk verba untuk pelaku tunggal sama dengan bentuk kala kini. Adapun bentuk jamak akan mengalami perubahan bunyi vokal akhir /e/ menjadi /o/.

(36) An kuluk mbi nangge. saya biasa ubi makan

'Saya biasa makan ubi'.

(37) Ar kuluk mbi kungge.

dia biasa ubi membeli

'Dia biasa membeli ubi'.

(38) Nir kuluk mbi nanggo.

kami biasa ubi makan

'Kami biasa makan ubi'.

(39) Kir kuluk mbi kunggo.

kalian biasa ubi makan

'Kalian biasa membeli ubi' .

\section{SIMPULAN}

Simpulan yang dapat ditarik dari uraian di atas adalah bentuk verba BDB mengandung makna temporalitas yang diungkap dalam bentuk penanda waktu kejadian yang lazim disebut temporalitas. Verba temporalitas ini memiliki sembilan bentuk. Bentuk itu mencerminkan pelaku dan waktu terjadinya peristiwa yang berbeda satu dengan lainnya. Pelaku dibedakan menjadi tunggal dan jamak, sedangkan waktu meliputi kini, lampau dekat, lampau jauh, dan mendatang kemudian ditambah satu verba kala ke- biasaan. Kesembilan bentuk itu ialah: 1) Verba Berpelaku Tunggal Kala Kini, 2) Verba Berpelaku Tunggal Kala Lampau Dekat, 3) Verba Berpelaku Tunggal Kala Lampau Jauh, 4) Verba Berpelaku Tunggal Kala Mendatang, 5) Verba Berpelaku Jamak Kala kini, 6) Verba Berpelaku Jamak Kala Lampau Dekat, 7) Verba Berpelaku Jamak Kala Lampau Jauh, 8) Verba Berpelaku Jamak Kala Mendatang, dan 9) Verba Kala Kebiasaan

\section{UCAPAN TERIMA KASIH}

Kajian ini tidak terlepas dari campur tangan berbagai pihak terutama sejawat di PBS FKIP Uncen. Ucapan terima kasih disampaikan terutama kepada Sdr. T. Purba dkk. yang telah melakukan penelitian pendahuluan sehingga datanya dapat digunakan dalam kajian ini. Teman sejawat lainnya yang telah memberikan informasi tambahan dan koreksi,serta sejawat lain yang tidak dapat disebut di sini. Semoga Allah menilai bantuan dan sumbangan Sdr. sebagai ibadah terbaik untuk saya di hadapan-Nya.

\section{DAFTAR PUSTAKA}

Alwi, Hasan dkk. 1998. Tata bahasa Baku Bahasa Indonesia. Jakarta: Balai Pustaka.

Briton, Laurel J. 1990. The Development of English Aspectual Systems. Cambridge Univerrsity Press.

Dahl, Osten. 1981. "On the Definition of the Telic - Telic (bounded-nonbounded) Distinction", dlm Tedeshi Philip J \& Annie Zaenen, Syntax and Semantics: Tense and Aspect. Vol 14.

Djajasudarma, T. Fatimah. 1990. "Situasi Telis - Telis dan Keaspekan Perspektif - Imperpektif Melalui Verba Dinamis - Statif" Linguistik Indonesia. Th. 8 No 1.

Djajasudarma. 1993a. Metode Linguistik: Ancangan Metode Penelitian dan Kajian. Bandung: Eresco. 
Fautngil, Crist. Dkk. 1991.Struktur Sintaksis Bahasa Biak. Laporan Penelitian. Jakarta: Pusat Pembinaan dan Pengembangan Bahasa.

Fokker, A.A. 1950. Beknopte Grammatica van de Bahasa Indonesia. J.B. Wolters, Groningen- Jakarta.

Jakarimilena, Nico. 1986. Struktur Bahasa Skow. Laporan Penelitian. Jakata: Kanwil Depdikbud Irja.

Mahsun. 2012. Metode Penelitian Bahasa: Tahapan Strategi, metode, dan tekniknya. Edisi Revisi. Jakarta: PT RajaGrafindo Persada.

Purba, Th. T. dkk. 1994. Morfologi Bahasa Dani barat. Dibiayai oleh: DP3M. Jayapura: FKIP Unoversitas Cenderawasih.

Purba, Th. T. Dkk. 2000. Variasi Struktur Bahasa Daerah di Irian Jaya. Jurnal MLI Tahun 18, Nomor 1, Hlm: 77-98, Februari 2000.

Riyono, Ahdi. 2009. Pengungkapan Makna Aspektualitas Reduplikasi dalam Bahasa Jawa: Kajian Morfologi. Ahdiriyono. blogspot.com, diakses Desember 2013.

Rostini, Titin. 2011. Perihal Aspek-tualitas danSistem Kala dalam Bahasa Jepang: Suatu Kajian Morfologi dan Semantik. Dlm Jurnal Humaniora. Vol 23 No 2
Sudaryanto, 1995. Bahasa dan Cara Penangannya. Yogyakarta: Kanisius.

Sumarlam, 1994. Keaspekan dalam Bahasa Jawa. Program Pascasarjana, Kajian Utama Linguistik. Bandung: Universitas Padjadjaran.

Silzer, Peter J. And Helja Haikinen. 1984. Index of Irian Jaya Languages. SIL: Jayapura

Tajuddin, Moh. 1992. Pengungkapan Makna Aspektualitas Bahasa Rusia dalam Bahasa Indonesia: Suatu Telaah tentang Aspek dan Aksionalitas. Disertasi. Bandung: Padjadjaran.

Tajuddin, Moh. 1993a. Pengungkapan Makna Aspektualitas Bahasa Rusia dalam Bahasa Indonesia: Suatu Telaah tentang Aspek dan Aksionalitas. (Disertasi, 1992) Proyek Penelitian dan Pembinaan Bahasa dan Sastra Indonesia dan Daerah. Jakarta: Departemen Pendidikan dan Kebudayaan.

Tajuddin, Moh. 2005. Aspektualitas dalam Kajian Linguistik. Bandung: PT. Alumni.

Wedhawati dkk. 2001.Tata Bahasa Jawa Mutakhir. Jakarta: Pusat Bahasa.

Wurm, Stepen A. 1982. Papuan Languages of Oceania. Tubingen: Gunter Naar Verlag Tubingen. 